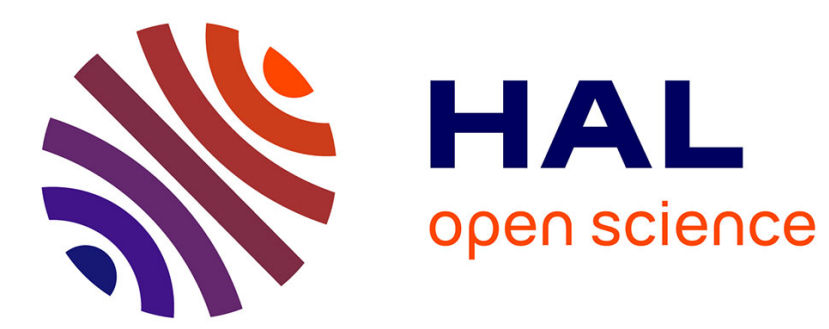

\title{
STUDY OF DISLOCATION LOOPS IN ALKALI HALIDE CRYSTALS BY DIFFUSE X-RAY SCATTERING
}

H. Spalt

\section{- To cite this version:}

H. Spalt. STUDY OF DISLOCATION LOOPS IN ALKALI HALIDE CRYSTALS BY DIFFUSE X-RAY SCATTERING. Journal de Physique Colloques, 1976, 37 (C7), pp.C7-507-C7-509. 10.1051/jphyscol:19767115 . jpa-00216837

\section{HAL Id: jpa-00216837 https://hal.science/jpa-00216837}

Submitted on 1 Jan 1976

HAL is a multi-disciplinary open access archive for the deposit and dissemination of scientific research documents, whether they are published or not. The documents may come from teaching and research institutions in France or abroad, or from public or private research centers.
L'archive ouverte pluridisciplinaire HAL, est destinée au dépôt et à la diffusion de documents scientifiques de niveau recherche, publiés ou non, émanant des établissements d'enseignement et de recherche français ou étrangers, des laboratoires publics ou privés. 


\title{
STUDY OF DISLOCATION LOOPS IN ALKALI HALIDE CRYSTALS BY DIFFUSE X-RAY SCATTERING
}

\author{
H. SPALT
}

Institut I für Festkörperphysik der Techn. Hochschule Darmstadt 6100 Darmstadt R.F.A.

\begin{abstract}
Résumé. - C'est un fait connu depuis quelque temps que des oscillations d'intensité caractéristique se produisent dans les figures de diffraction diffuse du fait du champ de déplacement de gros défauts tels que les amas et les boucles de dislocations. A côté de la diffraction due au champ de déplacement, la structure centrale des défauts étendus peut engendrer une ligne supplémentaire près des pics de Bragg. Ce n'est que récemment qu'il a été prouvé théoriquement qu'il y a pour les boucles de dislocation une corrélation entre les oscillations et cette ligne supplémentaire. La position de la ligne supplémentaire par rapport à un point voisin du réseau réciproque dépend de l'orientation du vecteur de Burgers et du vecteur du réseau réciproque.

Des résultats de diffraction diffuse des rayons $X$ sur des cristaux d'halogénures alcalins irradiés contenant de grands amas de défauts sont présentés. Les résultats sont discutés en termes de boucles dont les rayons dépendent des doses.
\end{abstract}

\begin{abstract}
It has been known for some time that characteristic intensity oscillations occur in diffuse scattering patterns due to the displacement field of strong defects like clusters and dislocation loops. Besides the scattering of the displacement field the core structure of extended defects may cause an extra line close to the Bragg-peak. Only recently it has been found theoretically that for dislocation loops there is a correlation between oscillations and the extra line. The position of the extra line relative to a nearby reciprocal lattice point depends on the orientation of the Burgers vector and the reciprocal lattice vector as well.

$X$-ray diffuse scattering results on irradiated alkali halide crystals containing large defect clusters are presented. Results are discussed in terms of loops with dose - dependend size.
\end{abstract}

$\mathrm{X}$-ray diffuse scattering has become a very useful method to determine the mechanical properties of point defects. Though conditions may be more complicated, informations on the properties of defect clusters can be given as well.

Experimentally diffuse scattering is determined as the difference of X-ray intensities scattered by a crystal before and after irradiation. For an analysis of the results it is useful to plot diffuse scattering intensity versus a vector $\mathbf{g}=\mathbf{K}-\mathbf{G}$ of reciprocal space, which is a measure of the distance from the closest reciprocal lattice point ( $\mathbf{K}$ scattering vector, $\mathbf{G}$ reciprocal lattice vector). For point defects it is found experimentally and theoretically as well, that the diffuse intensity decreases with a power law $\propto 1 / g^{2}$ (Huang scattering). As an example the upper curve of figure 1 shows the results of $\mathrm{KBr}$ irradiated at $6 \mathrm{~K} \mathrm{[1].} \mathrm{As} \mathrm{the} \mathrm{crystal} \mathrm{is} \mathrm{warmed}$ up, part of the defects created at low temperature recombine. Afier heating to $70 \mathrm{~K}$ and $100 \mathrm{~K}$ the scattering characteristics have changed. Apart from the region $\propto 1 / g^{2}$ still present, a second region $\propto 1 / g^{4}$ is found. This region normally called asymptotic scattering can be attributed to the existence of defect clușters.
From a detailed theoretical discussion [2] further characteristic properties of the scattering from clusters are known. Considering an interstitial type dislocation loop as one possible model of a defect cluster we find that the lattice is compressed on a line perpendicular to the centre of the loop. Therefore this part of the crystal will contribute intensity on the high angle side of a Bragg-reflection (positive $g$ ) only. Two areas of equal local lattice spacing will scatter into the same volume element of reciprocal space. And depending on the optical path difference between them interference can be constructive or destructive giving rise to intensity oscillations superimposed on the $1 / g^{4}$ dependence of asymptotic scattering.

Within a sphere of radius $R$ around the core of the loop the lattice strain is approximately constant and of the order of $\mathbf{b} / R$ (b Burgers vector). This is the maximum possible lattice strain and therefore diffuse scattering will not occur beyond a maximum value of $g$. The core structure mentioned will contribute an extra line as a last oscillation maximum. No oscillations are predicted at negative $g$. For vacancy type loops conditions for positive and negative $g$ are just reversed. 


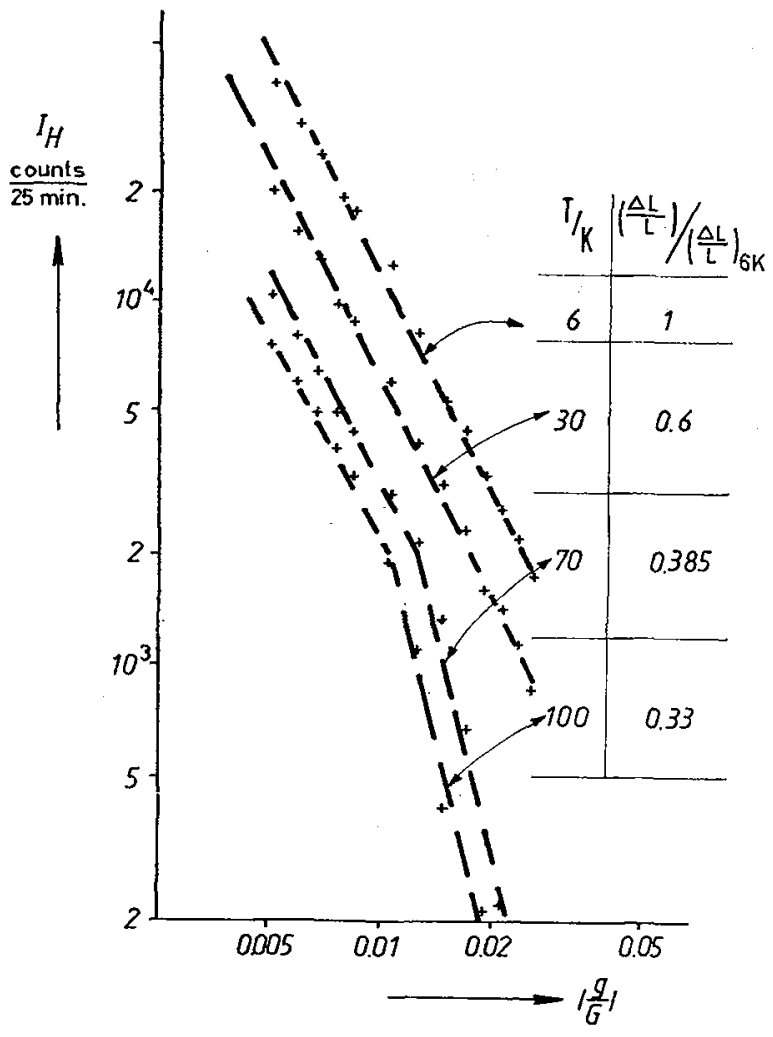

FIG. 1. - Diffuse scattering near the (600) reflection of $\mathrm{KBr}$ $\mathrm{X}$-irradiated at $6 \mathrm{~K}$ and after heating to various temperatures.

For the analysis of experimental results it has proven helpful to plot $g^{4}$. $I_{\mathrm{D}}$ instead of $I_{\mathrm{D}}$ versus $g$. Figure 2 shows in the lower section results on the (400) reflection

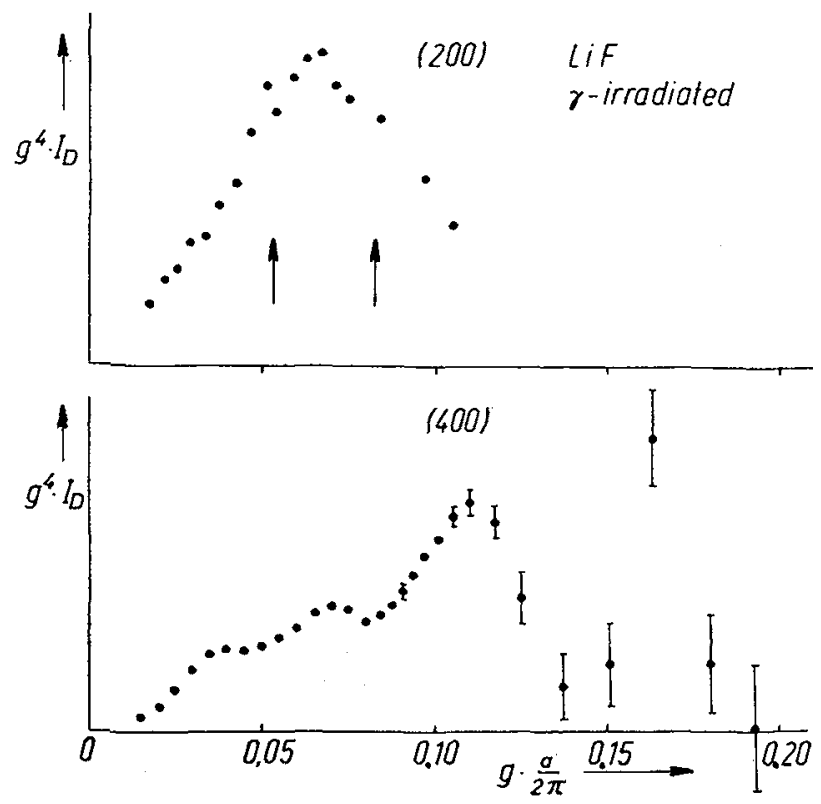

FIG. 2. - Diffuse scattering $I_{D} . g^{4}$ of $\gamma$-irradiated LiF. Arrows in the upper section (200) indicate the positions of the first and the last maximum as determined from the (400) reflection (lower section). of $\gamma$-irradiated LiF [3], which were the first experimental evidence of intensity oscillations. The first maximum is given by the change from Huang to asymptotic behaviour. It's position depends on the reciprocal lattice vector as $1 / \sqrt{\mathbf{G}}$. The position of the last maximum is given by $\mathbf{G} \cdot \mathbf{b} / R$. Now we reexamined the data of the (200) reflection shown in the upper section of figure 2. The positions of the first and the last maxima as extrapolated from the (400) results are indicated by arrows. Both maxima are so close to each other that they overlap and form one single peak, which could not be understood before. From the position of the last maximum we estimate the ratio of loop radius to Burgers vector to $R / \mathbf{b} \approx 25$.

On the negative side not shown here the curves are flat, indicating that there are no vacancy clusters, at least if there are they don't cause lattice strain.

After neutron-irradiation [4] the defect structure is expected to be more complicated because of defect production by high energy recoil particles from a nuclear reaction. Instead of four peaks we found two peaks only (Fig. 3). In addition it can be seen that the

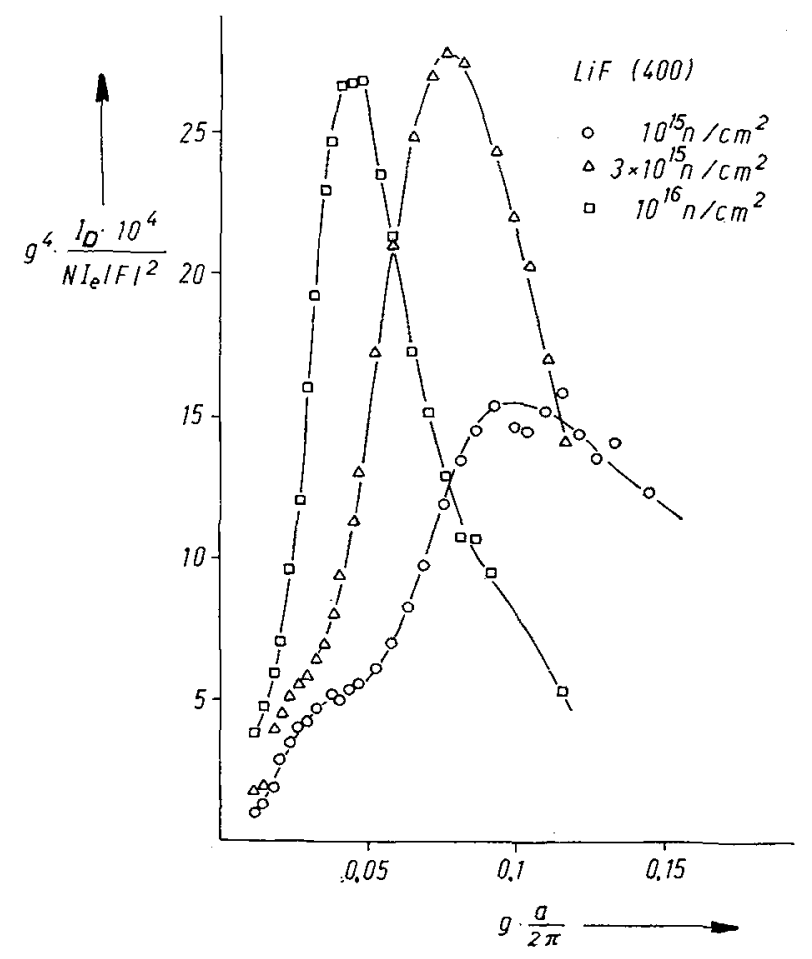

FIG. 3. - Diffuse scattering $I \mathrm{D} \cdot g^{4}$ near the (400) reflection of neutron-irradiated LiF.

peaks are shifted towards the reciprocal lattice point with increasing irradiation dose. This means the loops grow in size. Comparing these results with the (200) reflection again we find good agreement with the requirements for the dependence of peak positions on the reciprocal lattice vector. In this case the ratio of $R / \mathbf{b}=40,50$, and 90 for the three doses respectively. 
To come to a better description of small clusters, we $\gamma$-irradiated a crystal with a very small dose. The relative $F$ centre concentration was less than $10^{-5}$. Surprisingly the distribution of scattered intensity

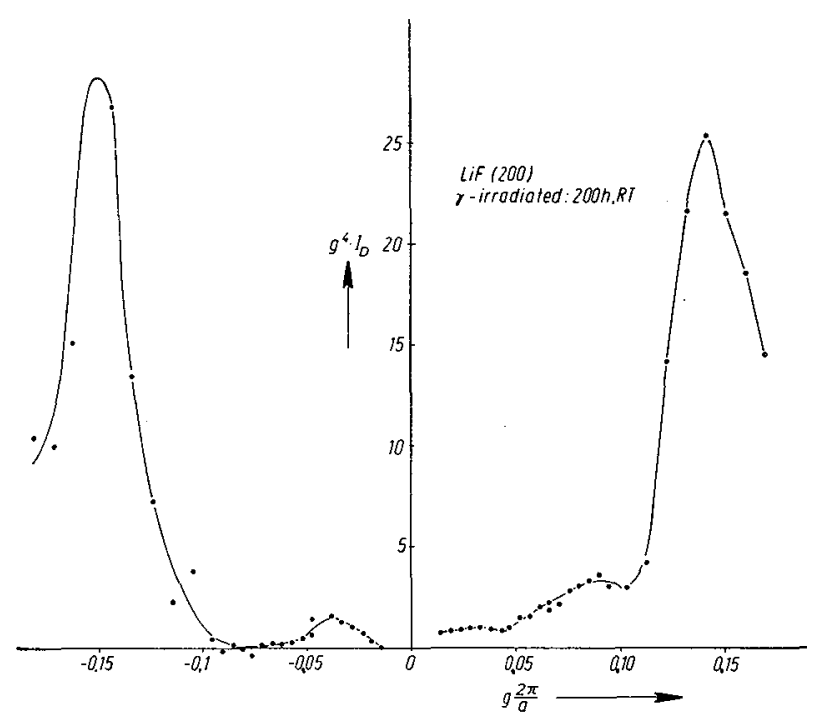

FIG. 4. - Diffuse scattering $I_{\mathrm{D}} \cdot g^{4}$ near the $(200)$ reflection of $\gamma$-irradiated $\mathrm{LiF}$ at low F-centre concentration. looks quite different now (Fig. 4). In the case of (200) reflections we always had only one broad peak extending over the whole area. Now we find three different peaks at positive $g$. Furthermore we could not find a correlation of peaks in this and the (400) pattern as it was possible before. But the most marked difference is, that we have a structure at negative $g$ values indicating the presence of vacancy type clusters.

How do we interpret these results and the difference as compared with previous measurements ?

1) We can be sure that we are dealing with clustering processes on $(100)$ planes because scattering in the vicinity of (220) and (222) type reflections is at least one order of magnitude lower than for (200) type reflections.

2) Most probably the key for the understanding of the phenomena is the low defect concentration. At low concentrations clustering processes will to a large extend be influenced by the defects present in the crystal prior to irradiation predominantly dislocations. So we think our results are evidence of these influences.

Further investigations of crystals with well known dislocation structures and impurities will be necessary to reach a better understanding of the diffraction patterns presented.

\section{References}

[1] Lohstöter, H., Spalt, H. and Peist, H., Phys. Rev. Lett. 29 (1972) 224.

[2] Trinkhaus, H., Z. Naturforsch. 28a (1973) 980 and private communication.

[3] Trinkhaus, H., Spalt, H. and Peisl, H., Phys. Status Solidi (a) 2 (1970) K 97.

[4] Giersberg, E.-J. Diplomarbeit TH Darmstadt 1973.

\section{DISCUSSION}

G. Guillot. - Have you experimental evidence of dislocation loops in crystals irradiated at liquid nitrogen temperature?

H. Spalt. - There are no experiments by now. We have investigated $\mathrm{KBr}$ irradiated at $6 \mathrm{~K}$ and warmed to $70 \mathrm{~K}$ and $100 \mathrm{~K}$ and $\mathrm{LiF} \gamma$-and neutron-irradiated at room temperature. But we plan to do some LNT experiments in the near future. 